\title{
Comprehensive Simulator (CSFMB) Applied to Circulating Fluidized Bed Boilers and Gasifiers
}

\author{
Marcio L. de Souza-Santos* \\ University of Campinas (UNICAMP), Faculty of Mechanical Engineering, Department of Energy, CP 6122, Campinas, \\ SP 13083-970, Brazil
}

\begin{abstract}
A comprehensive simulation program of bubbling fluidized beds (CSFB or CSFMB) has been able to reproduce operations of circulating fluidized beds. The main considerations that allow such application as well comparisons between simulation results and real operational data are shown. In addition, criteria for scaling-up pilot operations to industrial units are illustrated.
\end{abstract}

Keywords: CSFB, CSFMB, circulating fluidized bed, modeling, simulation, boilers, gasifiers.

\section{INTRODUCTION}

Recent publications have shown how well a new version of a mathematical model and simulation program (CSFB or CSFMB) is capable of reproducing boilers and gasifiers operational conditions working under bubbling fluidized bed $[1,2]$. That is the product of several improvements introduced during the last 20 years since the first version of the mathematical model and respective simulation program [325]. Among the simulated types of units, there were: boilers, gasifiers, shale retorting reactors, dryers and pyrolysers consuming various coal ranks and biomasses.

After that, further expansions on the applicability of the model and simulation program allowed CSFMB to reproduce real operation with circulating fluidized units. Basic details for such a task are shown below. Having in mind the relatively low deviations, the paper illustrates an exercise on scaling-up the pilot operation to a large industrial unit.

\section{MODEL}

It is important to notice that the terms dense and lean regions in circulating beds are the equivalent of bed and freeboard in the cases bubbling techniques, respectively. Therefore, if the results refer to bed and freeboard, they should be respectively understood as dense and lean regions.

Details of the most recent version for cases of bubbling fluidized beds have been recently published $[1,2]$ and are not repeated here. As seen, the program is also applicable to bubbling fluidized units operating with partial or complete re-injection into the bed of particles collected at the cyclone system. Bubbling and circulating bed operations are similar in several ways, however there are noticeable differences and the most important are briefly commented below:

- For the same average particle size and density of particles in a bed, circulating equipment operate under higher superficial gas velocities than

*Address correspondence to this author at the University of Campinas (UNICAMP), Faculty of Mechanical Engineering, Department of Energy, CP 6122, Campinas, SP 13083-970, Brazil; E-mail: dss@ fem.unicamp.br bubbling ones. On the other, there is a large intersection between the dynamics of bubbling and circulating bed fluidization $[1,26]$.

- $\quad$ Circulating beds usually operate with larger bubbles when compared to the equivalent bubbling ones. In most of the cases, circulating fluidization leads to slugging flow or bubble taking the entire crosssectional area of the bed or dense region. This greatly decreases the mass or solids held in that region, thus most of the particles are found in the lean region. This implies that a considerable fraction of transformations or gas-solid reactions take place in the lean region as well.

After analyzing the differences between bubbling and circulating fluidization it became clear that the model developed for bubbling process [1-25] could be adapted to simulate circulating ones as long that new strategy to compute the freeboard or lean region were revised. The first task was to verify the best model to predict the void fraction profile in the lean region. Of course, a large number of papers on this subject can be found through the literature and an excellent review is presented by Pécora [27-29]. It has been verified [30-43] that one-dimensional attacks also provide reasonable descriptions of the void fraction according to the vertical position at the lean region. In particular, Rhodes and Geldart [36] describe a detailed discussion on the phenomena in the lean region. Among other details, their conclusions justify the application of Wen and Chen's relation [44] describing the flux of solid against the height in the freeboard or lean region. Those relations have been used in CSFMB model since its first version $[3,4]$ and more details can also be found elsewhere $[1,2]$ (see, for instance, relations A.30, A.31, and A.32 at ref. [2]). Those were adopted also for the present case of circulating fluidized beds.

Another point to be inserted into the existing model and simulation program was the method by which the height of dense region would be computed. For that, equalization of pressure between the raising column and the particle returning column at the reinjection position should be observed. The model for that was taken from the work of Pécora [27- 
29]. Of course, the relations concerning to energy and mass balances for the dense and lean regions continue to be valid and similar to the applied before [1-2]. In addition, the relationships used to predict the operation of cyclone system were similarly applied, including computations to provide the heat transfers between the returning leg and surroundings.

\section{SIMULATION PROCEDURE}

The first successful version of CSFMB was finished in 1987 [3, 4]. Since then, the model and simulation program have been improved [1] and the last version described in a recent paper [2].

The adaptation of that model for cases of circulating applies a similar strategy as for the bubbling process (Fig. 1), however with few improvements.

The main difference concerns to the fact that, in circulating bed units, most of the important processes occur in the lean region. Therefore, the convergence regarding conversion of solid species into gas components includes not only the dense region, but also the lean one. The basic assumptions and computational strategy can be summarized as follows:

1) The unit operates in steady-state regime.

2) The equipment is separated in two main regions: dense region (or bed in cases of bubbling condition) and lean region (or freeboard in bubbling processes).
3) The dense region is divided in two main phases: bubble and emulsion.

4) There are three possible solid phases: fuel, inert, and sulfur absorbent such as limestone, dolomite or mixture of those. Ash, eventually detached from the spent fuel, would constitute part of the inert solid phase.

5) The emulsion is composed by solid particles and percolating gas.

6) Despite the fast fluidization regimes found in circulating beds, the contributions for gas-solid reactions from particles in the bubbles are neglected. Future versions may drop this simplification.

7) Emulsion gas is considered inviscid, therefore rises through the bed in a plug-flow regime.

8) The same as above is assumed for the bubble gas. However, dimensions, raising velocity, fraction of bed volume occupied by bubbles, as well other characteristics of bubbles are considered in all calculations regarding that phase.

9) Bubbles and emulsion exchange mass and heat.

10) Heat transfers also occur between all phases, including particles.

11) Gases are assumed transparent regarding radiative heat transfers.

12) Emulsion gas exchanges heat with the vessel or reactor walls. Therefore, all heat transfers between the

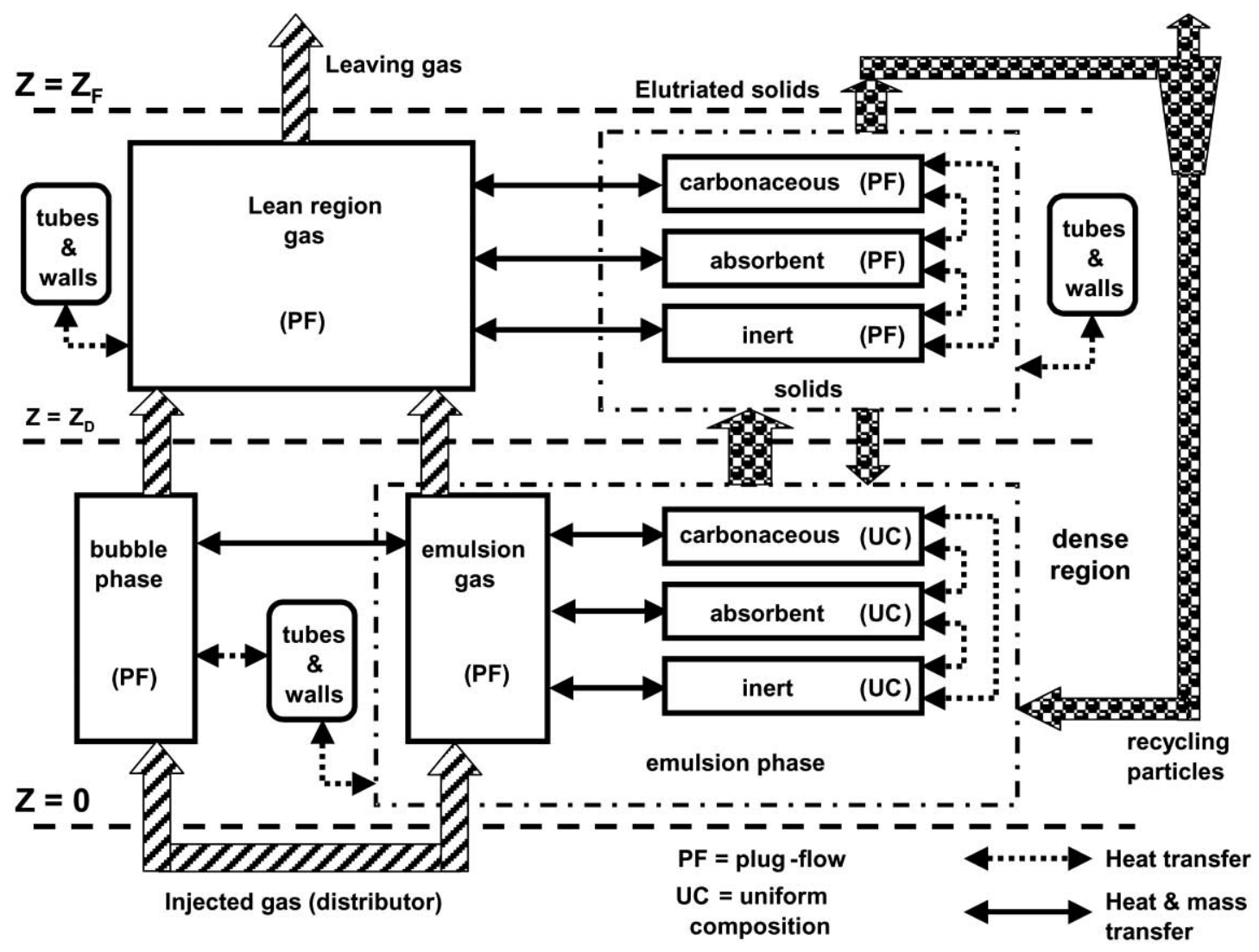

Fig. (1). Simplified diagram showing the basic aspects and assumptions of the model for circulating fluidized bed equipment. 
walls and other phases (bubbles and particles) take place indirectly through the emulsion gas.

13) All phases exchange heat with eventually immersed surfaces (such as tube banks) in the dense and lean regions.

14) Mass transfers occur between particles and emulsion gas as well between bubbles and emulsion.

15) An average uniform composition for each solid particle is computed in the dense region through convergence procedures involving the solutions of differential mass and energy balances described elsewhere [14]. However, their composition may change in the lean region. In addition, particles may present large gradients of temperature and composition in the dense and lean regions.

16) Compositions and temperatures of all gas and solid phases vary in the lean region and are computed using complete differential and energy balances [1-4].

17) Usually, circulating bed boilers generate steam using external exchangers. Therefore, tube banks are not found inside the dense or lean regions. Despite that, the present version is prepared to contemplate even such remote possibility. Thus, all equations related to heat transfers from the bed to the tube surfaces causing phase changes inside the tubes are added to the simulator.

18) Particle size distributions modify due to chemical reactions, attritions between particles themselves, as well due to the entrainment and recirculation processes. All those are taken into account to compute the size distributions of each solid phase in the dense and lean regions.

19) Heat and mass transfers in the axial or vertical direction within each phase are considered negligible when compared with the respective transfers in the radial or horizontal direction between a phase and neighboring ones.

20) At each axial position (z), mass transfers between phases result from differences of species average concentrations at each phase. As soon chemical species are consumed or formed by reactions, they are subtracted from or added to the respective phase. Therefore, these effects appear as sink or source terms in the mass continuity equations for each phase [1-4].

21) At each axial position ( $\mathrm{z}$ ), heat transfers between phases result from differences of temperature at each phase. These terms would appear as sinks or sources in the energy conservation equations [1-4].

22) At the basis of the dense region ( $\mathrm{z}=0)$, the two-phase model $[1-4,45]$ is applied to determine the splitting of injected gas stream between emulsion and bubble phases.

23) For points above that ( $z>0)$, the mass flow in each phase is determined by fundamental equations of transport phenomena. Those include mass transfers between the various phase as well homogeneous and heterogeneous reactions.
24) Boundary conditions for the gas phases concerning temperature, pressure and composition at $(\mathrm{z}=0)$ are given by the values of injected gas stream.

25) At each iteration, boundary conditions for the three possible solid phases (carbonaceous, sulfur absorbent, and inert) are obtained after differential energy balances involving conduction, convection, and radiative heat transfers between the distributor surface and the various phases.

26) The solution of differential equations describing the energy and mass transfers proceed from the distributor $(\mathrm{z}=0)$ to the top of lean region $\left(\mathrm{z}=\mathrm{z}_{\mathrm{F}}\right)$. The values at the top of the dense region $\left(\mathrm{z}=\mathrm{z}_{\mathrm{D}}\right)$ are used as boundary conditions for the bottom of lean one.

27) An iterative process allows the determination of boundary conditions for the solid phases at $\mathrm{z}=0$. For the first iteration, a carbon conversion is assumed. After solving the system of coupled non-linear differential equations, the new carbon conversion is computed. Conversions of all other solid-phases components are computed as well.

28) The cyclone system is simulated and all characteristics of the collected particles are obtained. Those are used by the mass and energy balances during the next iteration.

29) Steps 25 to 28 are repeated until convergence regarding a weighted overall deviation is achieved. That weighing considers deviations between assumed and computed conversions of chemical species as well between assumed and computed heat transfers among phases and immersed surfaces in the bed and freeboard. This and the tight coupling of all chemical and physical phenomena involved in the equipment, ensures consistency regarding all mass and energy balances.

Once the simulation is concluded all internal and overall details of the equipment operation such as temperature, concentration, and all other variable profiles throughout the entire equipment, are printed. A new graphical interface facilitates the input of data for simulations as well consultation and study of outputs.

As seen above, despite taking into account heat and mass transfer between phases in the radial or horizontal direction, all variations on temperatures and concentrations are assumed to occur only in the axial direction (z). Therefore, this is a one-dimensional model. Regardless of that apparent simplicity, the solution of governing non-linear and tightly coupled system of differential equations provides a complete and detailed picture of all significant aspects inside the equipment.

Fundamental as well auxiliary equations of that model are presented elsewhere [1-2].

Comparisons between the simulation results and data obtained from real units are shown ahead.

\section{EXPERIMENTAL RESULTS}

The experimental tests were carried by the Department of Chemical and Biological Engineering at the University of 
Table 1. Main Design Data and Test Operational Conditions of Circulating Gasifier Units

\begin{tabular}{|c|c|c|}
\hline DETAIL & \multicolumn{2}{|l|}{ TEST } \\
\hline Fuel & Cypress & Hemlock \\
\hline \multicolumn{3}{|l|}{ Proximate analysis (w.b. \%) } \\
\hline Moisture & 9.70 & 8.80 \\
\hline Fixed Carbon & 13.98 & 14.17 \\
\hline Ash & 0.63 & 0.36 \\
\hline \multicolumn{3}{|l|}{ Ultimate analysis (\% d.b.) } \\
\hline $\mathrm{O}$ & 40.40 & 40.6 \\
\hline S & 0.45 & 0.38 \\
\hline HHV (d.b) (MJ/kg) & 20.3 & 20.3 \\
\hline Particle apparent density $\left(\mathrm{kg} / \mathrm{m}^{3}\right)^{\mathrm{a}}$ & 720 & 720 \\
\hline Particle real or skeletal density $\left(\mathrm{kg} / \mathrm{m}^{3}\right)^{\mathrm{a}}$ & 1750 & 1750 \\
\hline \multicolumn{3}{|l|}{ Basic Geometry } \\
\hline Dense region equivalent diameter $(\mathrm{m})$ & 0.100 & 0.100 \\
\hline Air flow through distributor $(\mathrm{kg} / \mathrm{s})$ & $1.63 \mathrm{E}-2$ & $1.75 \mathrm{E}-2$ \\
\hline Temperature of injected air $(\mathrm{K})$ & 433 & 433 \\
\hline Steam flow injected at $2 \mathrm{~m}$ above distributor $(\mathrm{kg} / \mathrm{s})$ & 0.0000 & $1.938 \mathrm{E}-4$ \\
\hline Temperature of injected steam $(\mathrm{K})$ & ---- & 425 \\
\hline Average pressure in the equipment $(\mathrm{kPa})$ & 105 & 105 \\
\hline
\end{tabular}

${ }^{a}$ approximate value.

British Columbia (UBC) in collaboration with the Chinese and Korean research institutions. Various biomasses were gasified in a $6.5 \mathrm{~m}$ high and $0.1 \mathrm{~m}$ internal diameter circulating bed pilot unit operating near atmospheric pressure. Air, injected through a porous plate, was used as gasification agent of various biomasses. Tests were conducted within 970-1120 $\mathrm{K}$ temperature interval and relatively wide range of feeding rates $[46,47]$. Although several details of the unit as well operations are reported, the author is very grateful to the research team at UBC for providing many other information required by CSFMB simulator.
The main operational conditions can be found elsewhere [46, 47] and are also summarized at Tables $\mathbf{1}$ and $\mathbf{2}$.

Comparisons between most significant simulation results and operational conditions simulator are summarized at Tables 3 and $\mathbf{4}$.

Additionally, various profiles of several important variables are illustrated from Figs. ( 2 to $\mathbf{8}$ ).

CSFMB performance was also verified against data obtained from a pilot circulating fluidized bed installed at the 
Table 2. Particle Size Distributions of Solid Fed into the Circulating Gasifier Units

\begin{tabular}{|c|c|c|c|c|c|c|c|}
\hline \multicolumn{4}{|c|}{ TEST 01} & \multicolumn{4}{|c|}{ TEST 07} \\
\hline \multicolumn{2}{|c|}{ BIOMASS } & \multicolumn{2}{|c|}{ INERT } & \multicolumn{2}{|c|}{ BIOMASS } & \multicolumn{2}{|c|}{ INERT } \\
\hline $\begin{array}{c}\text { Diameter } \\
\qquad(\mu \mathrm{m})^{*}\end{array}$ & $\begin{array}{c}\text { Mass } \\
\text { percentage }\end{array}$ & Diameter $(\mu \mathbf{m})^{*}$ & $\begin{array}{c}\text { Mass } \\
\text { percentage }\end{array}$ & $\begin{array}{c}\text { Diameter } \\
(\mu \mathbf{m})^{*}\end{array}$ & $\begin{array}{c}\text { Mass } \\
\text { percentage }\end{array}$ & $\begin{array}{c}\text { Diameter } \\
(\mu \mathbf{m})^{*}\end{array}$ & $\begin{array}{c}\text { Mass } \\
\text { percentage }\end{array}$ \\
\hline 4770 & 22.97 & 1400 & 0.70 & 6730 & 0.92 & 1400 & 0.70 \\
\hline 2590 & 34.47 & 710 & 73.13 & 4770 & 7.21 & 710 & 73.13 \\
\hline 2190 & 11.42 & 417 & 22.61 & 2590 & 10.81 & 417 & 22.61 \\
\hline 1850 & 6.14 & 250 & 3.46 & 2190 & 13.47 & 250 & 3.46 \\
\hline 1550 & 7.0 & 90 & 0.10 & 1850 & 6.51 & 90 & 0.10 \\
\hline 1060 & 12.24 & & & 1550 & 10.57 & & \\
\hline 564 & 2.84 & & & 1060 & 34.84 & & \\
\hline 334 & 1.56 & & & 564 & 8.98 & & \\
\hline 170 & 0.95 & & & 334 & 4.6 & & \\
\hline \multirow[t]{2}{*}{45} & 0.41 & & & 170 & 1.46 & & \\
\hline & & & & 45 & 0.63 & & \\
\hline
\end{tabular}

(*) Average of the slice with respective mass fraction.

Table 3. Composition of Gas Produced During Real Operations of Circulating Gasifier Units and Respective Simulation Results

\begin{tabular}{|c|c|c|c|c|}
\hline COMP. & \multicolumn{2}{|c|}{ TEST 01} & \multicolumn{2}{|c|}{ TEST 07} \\
\hline $\mathrm{H}_{2}$ & 5.6 & 5.7492 & 5.5 & 6.3172 \\
\hline $\mathrm{H}_{2} \mathrm{~S}$ & n.d. & 0.0403 & n.d. & 0.0470 \\
\hline $\mathrm{NH}_{3}$ & n.d. & 0.1240 & n.d. & 0.1630 \\
\hline $\mathrm{NO}_{2}$ & n.d. & 0.0000 & n.d. & 0.0000 \\
\hline $\mathrm{N}_{2}$ & 68.0 & 65.6250 & 59.5 & 61.6783 \\
\hline $\mathrm{N}_{2} \mathrm{O}$ & n.d. & 0.0000 & n.d. & 0.0000 \\
\hline $\mathrm{O}_{2}$ & n.d. & 0.0000 & n.d. & 0.0000 \\
\hline $\mathrm{CO}_{2}$ & 18.1 & 17.6723 & 15.0 & 16.9514 \\
\hline $\mathrm{HCN}$ & n.d. & 0.0010 & n.d. & 0.0023 \\
\hline $\mathrm{CH}_{4}$ & 1.4 & 2.1828 & 3.4 & 3.6239 \\
\hline $\mathrm{C}_{2} \mathrm{H}_{4}$ & n.d. & 0.0014 & n.d. & 0.0024 \\
\hline $\mathrm{C}_{2} \mathrm{H}_{6}$ & n.d. & 0.0003 & n.d. & 0.0006 \\
\hline $\mathrm{C}_{3} \mathrm{H}_{6}$ & n.d. & 0.0000 & n.d. & 0.0000 \\
\hline $\mathrm{C}_{3} \mathrm{H}_{8}$ & n.d. & 0.0000 & n.d. & 0.0000 \\
\hline
\end{tabular}


Table 4. Several Additional Operational Conditions During Real Operations of Circulating Gasifier Units and Respective Simulation Results

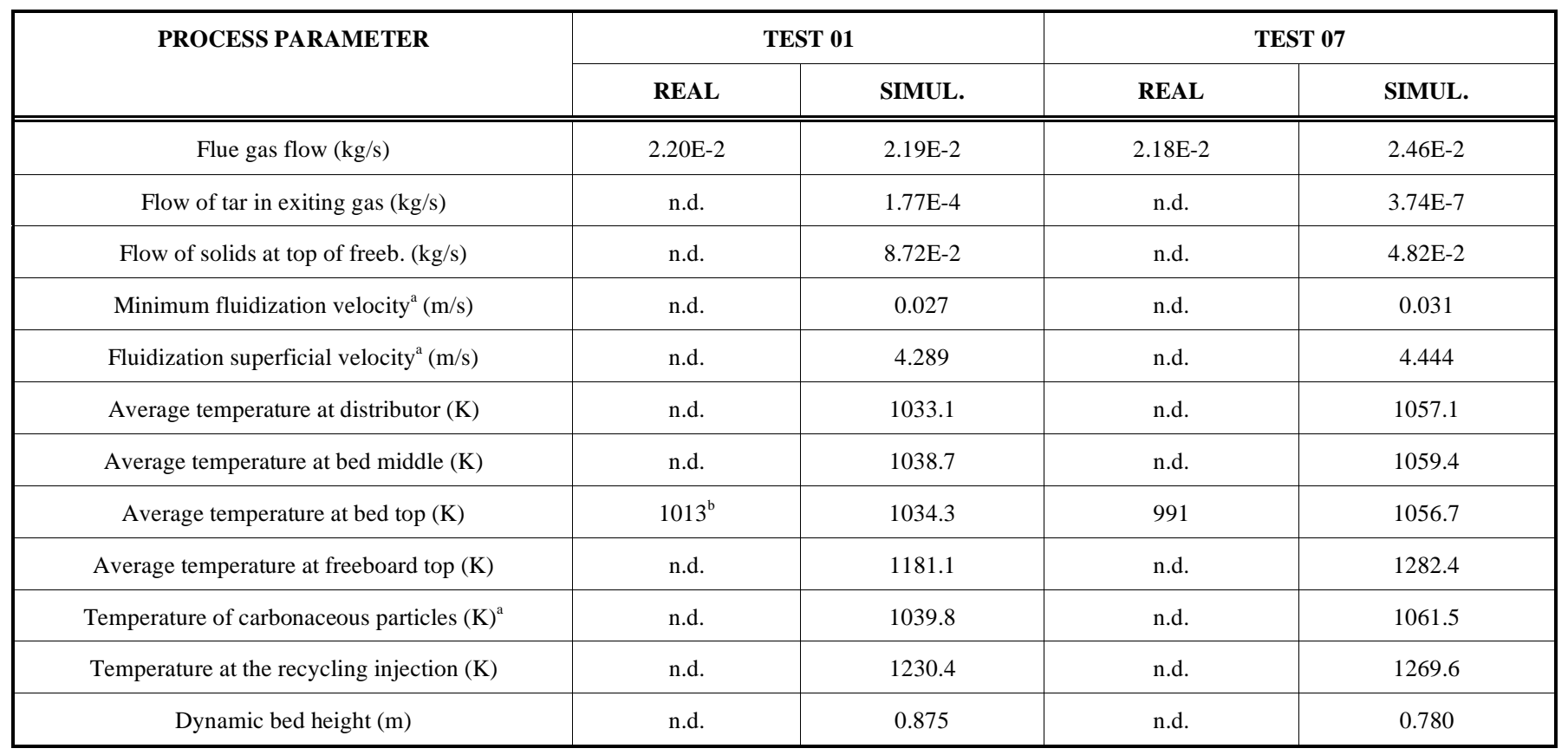

${ }^{\mathrm{a}}$ At the middle of the dense region. ${ }^{\mathrm{b}}$ Position not clearly specified in the report. n.d.: Not determined or reported.

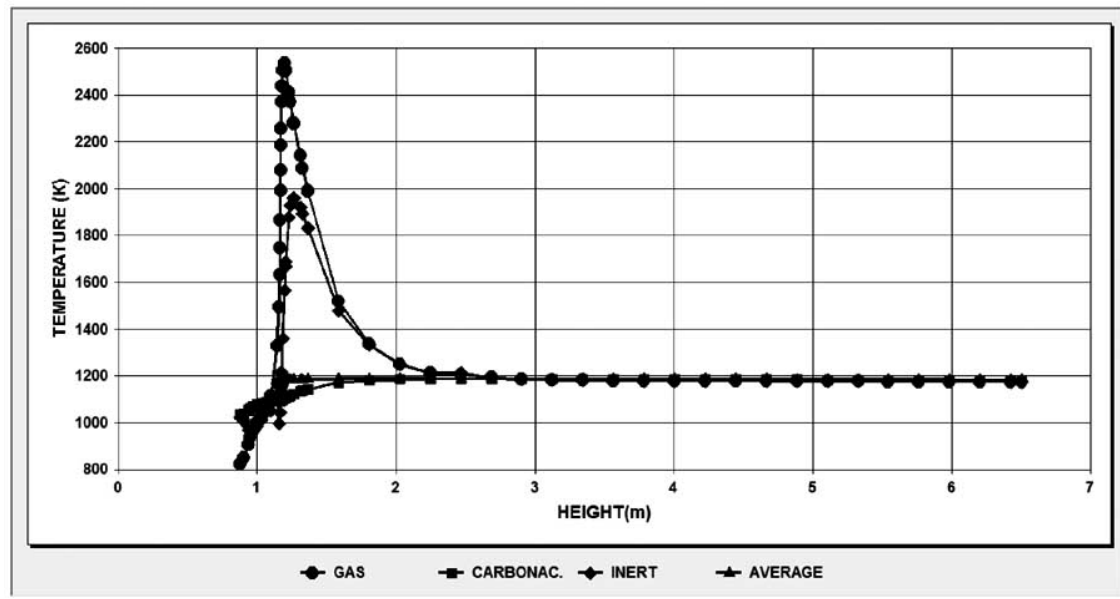

Fig. (2). Temperature profiles in the lean section obtained by simulation of Test 01 , UBC rig.

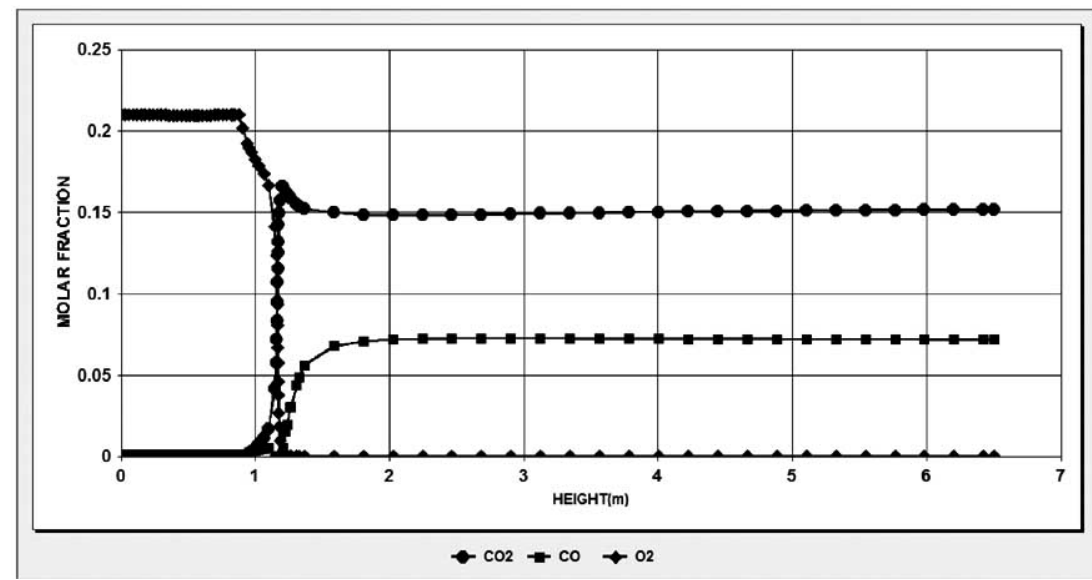

Fig. (3). $\mathrm{CO}_{2}, \mathrm{CO}$, and $\mathrm{O}_{2}$ concentration profiles through the entire equipment obtained by simulation of Test 01 , UBC rig. 


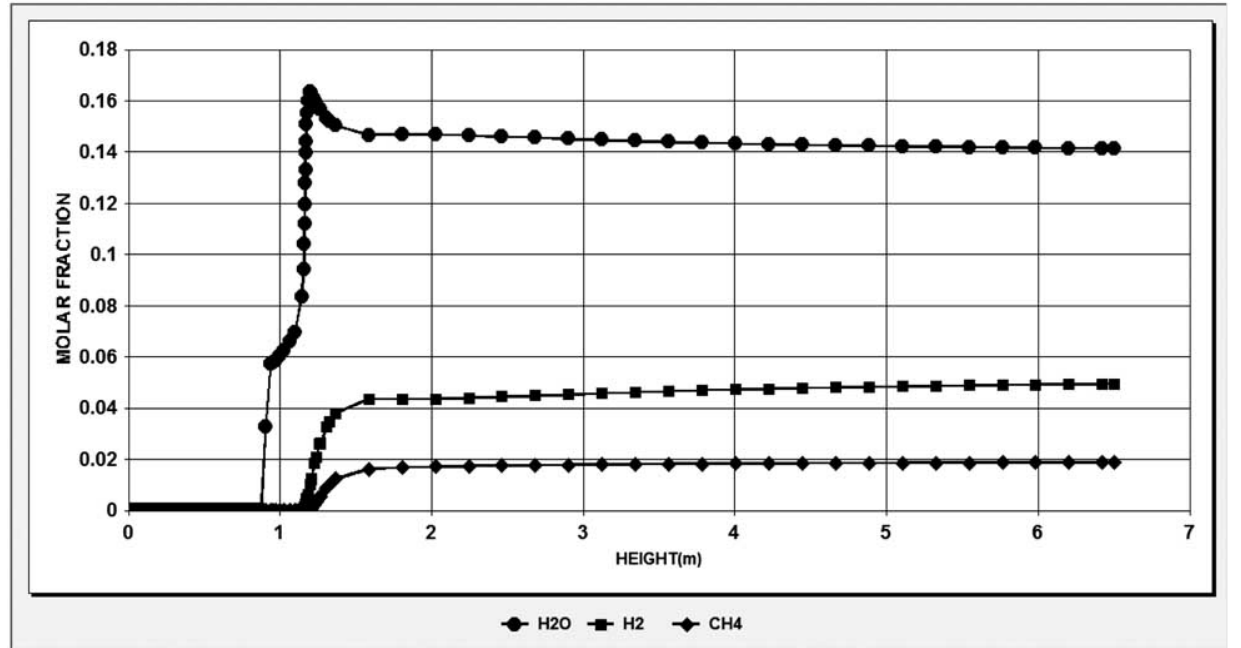

Fig. (4). $\mathrm{H}_{2} \mathrm{O}, \mathrm{H}_{2}$, and $\mathrm{CH}_{4}$ concentration profiles through the entire equipment obtained by simulation of Test 01 , UBC rig.

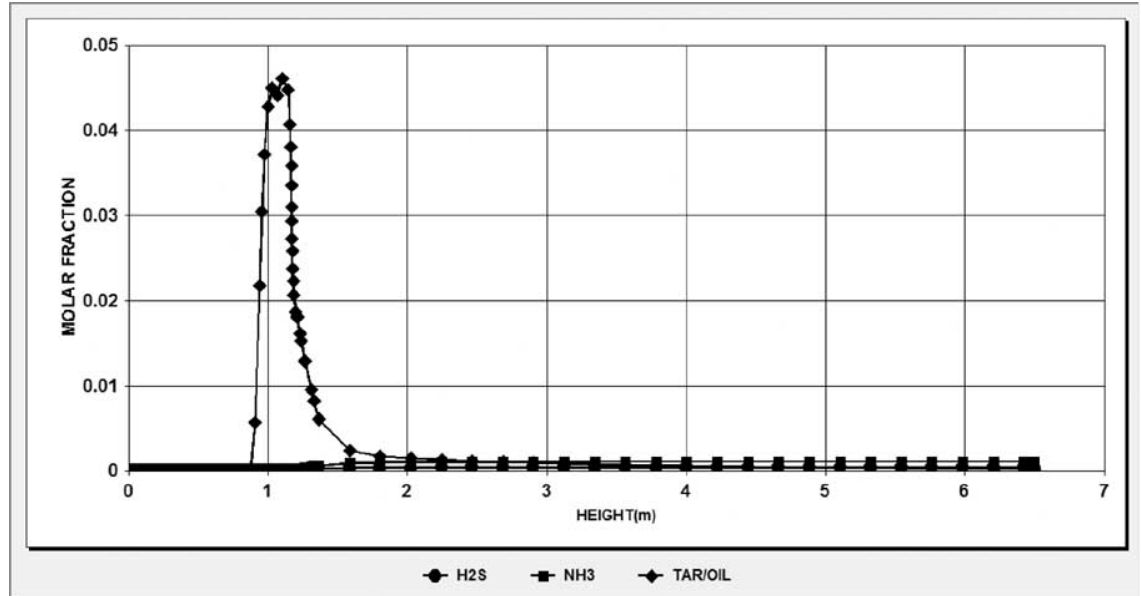

Fig. (5). Tar (or Oil) and other species concentration profiles through the entire equipment obtained by simulation of Test 01 , UBC rig.

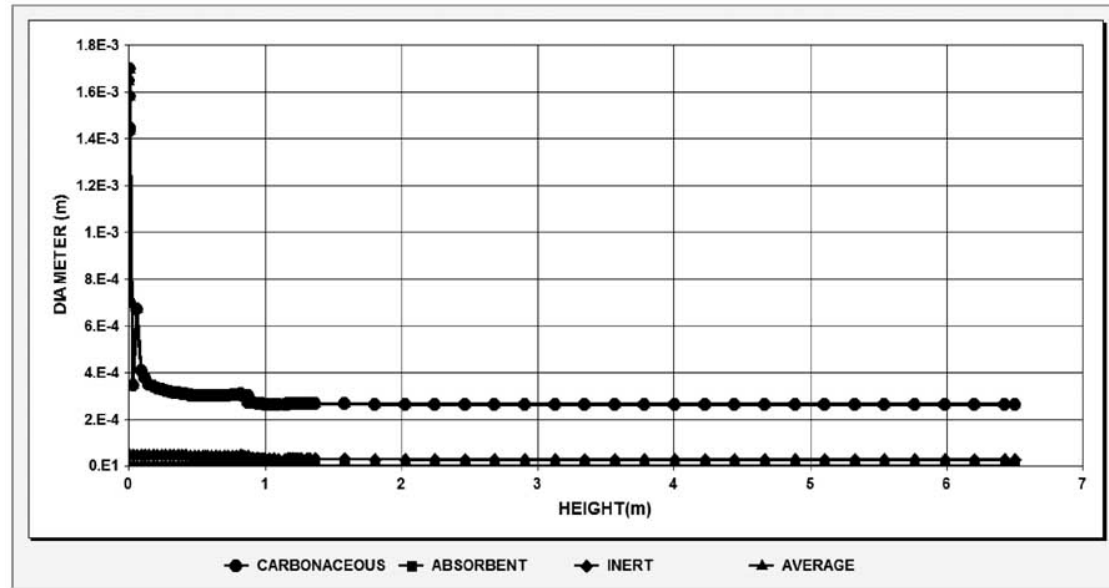

Fig. (6). Average diameter of particle species against vertical position during the simulation of Test 01, UBC rig. 


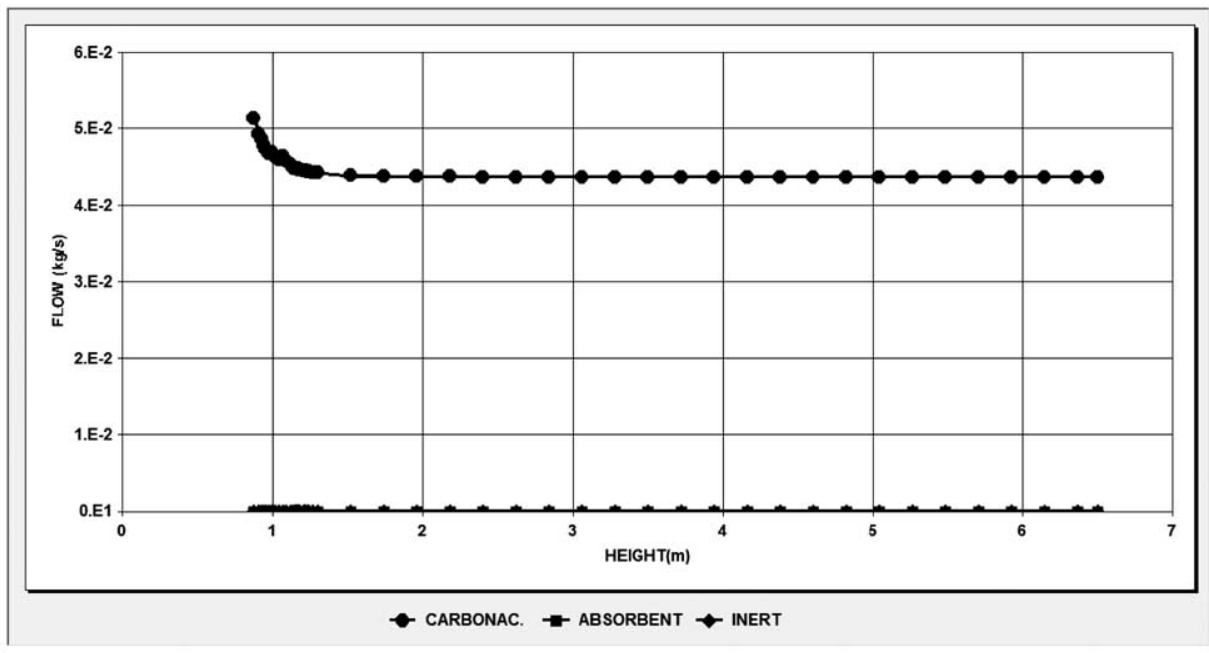

Fig. (7). Upward mass flow of solid particles against vertical position at the lean region obtained by simulation of Test 01, UBC unit.

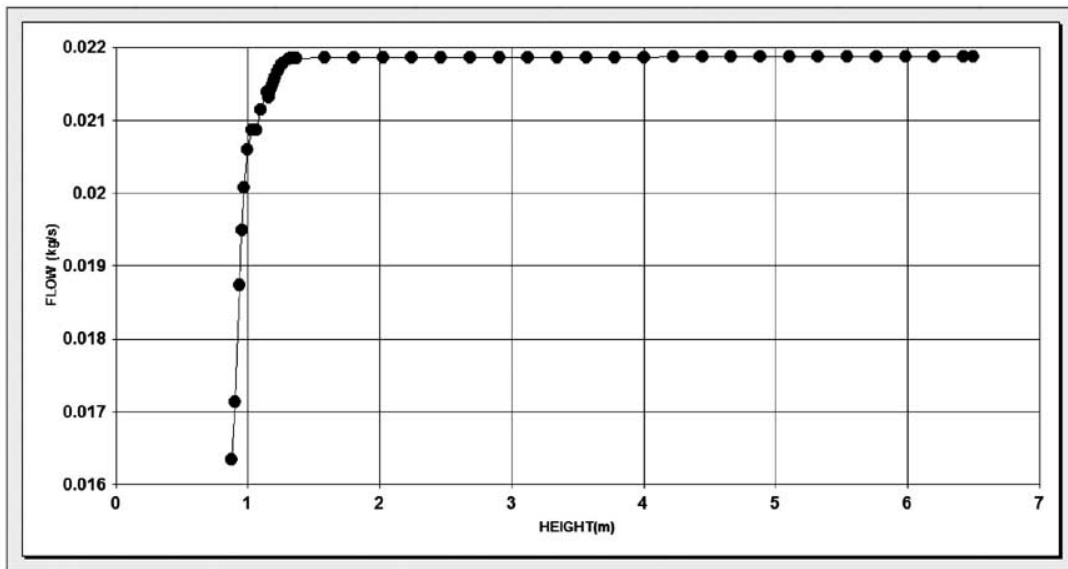

Fig. (8). Upward flow of gases against the vertical position at the lean region obtained by simulation of Test 01 , UBC unit.

State University of Campinas [27-29]. Table 5 shows the main dimensions and operational conditions of a test.

Several fluidization parameters are computed by the simulator, among them the dynamic height of dense region with value of $0.4 \mathrm{~m}$ and the mass flow of particles. The simulation result for the last one was $4.34 \times 10^{-2} \mathrm{~kg} / \mathrm{s}$, while the measured value during experiments was $3.86 \times 10^{-2} \mathrm{~kg} / \mathrm{s}$; therefore, a deviation around $10 \%$.

\section{DISCUSSION}

The results confirm that, differently from most bubbling cases, the dense region-which is the equivalent to bed in bubbling fluidization - is not the most important region in cases of circulating units. This is so because the lean region-which is the equivalent to freeboard in bubbling fluidization-concentrates almost all processes or phenomena for that last type of equipment. After a relatively stable temperature in the dense region, fast combustion of suspended fuel leads to steep variations of temperature (Fig. 2) and concentrations of several gases as well abruptly consumption of oxygen (Figs. 3 and 4 ) take place in the lean region. The sudden variations of temperature and concentrations in the gas phase were not only due to combustions, but also by the fast pyrolysis, which occur around the same position. Fig. (5) illustrates the tar production at that point as well its fast destruction by cracking and cooking just ahead the devolatilization peak. Thus, part of the fuel gases released by pyrolysis found an oxidizing atmosphere, resulting in sharp increase in the gas phase temperature (Fig. 2). Despite that, the average temperature show little variations, as would be confirmed by thermocouples placed throughout the equipment.

The test at cold condition showed that this first approximation is not too far from reality. Of course, the present approach is just an approximation, which applied relations from freeboard of bubbling beds to the lean region of circulating ones. Further improvements would allow better representations of the very complex dynamics taking place in the lean region of circulating fluidized equipment.

It is also important to notice few aspects related to the dynamics in the lean region. Of course, the size of particles and therefore the average diameter tends to decrease with the height. The variation is relatively gentle at cold conditions 
Table 5. Conditions of Circulating Bed Fluidization Carried at Unicamp

\begin{tabular}{|c|c|}
\hline DETAIL & TEST 43 \\
\hline \multicolumn{2}{|l|}{ Inert (sand) particles characteristics } \\
\hline Particle real or skeletal density $\left(\mathrm{kg} / \mathrm{m}^{3}\right)$ & 1394 \\
\hline Mass percentage of fed particles with avg. diameter around $0.920 \mathrm{~mm}$ & 80.00 \\
\hline \multicolumn{2}{|l|}{ Equipment basic geometry } \\
\hline Dense region equivalent diameter $(\mathrm{m})$ & 0.100 \\
\hline Lean region equivalent diameter $(\mathrm{m})$ & 0.100 \\
\hline Equipment height (m) & 4.000 \\
\hline Height of cyclone cylindrical section (m) & 0.328 \\
\hline Height of cyclone conical section (m) & 0.328 \\
\hline Internal diameter of recycling leg $(\mathrm{m})$ & 0.0603 \\
\hline Length of recycling tube $(\mathrm{m})$ & 3.10 \\
\hline Position (above the distributor) of particles re-injection in the bed (m) & 0.415 \\
\hline \multicolumn{2}{|l|}{ Injected gas } \\
\hline Air flow through distributor (kg/s) & 0.043 \\
\hline
\end{tabular}

a approximate value.

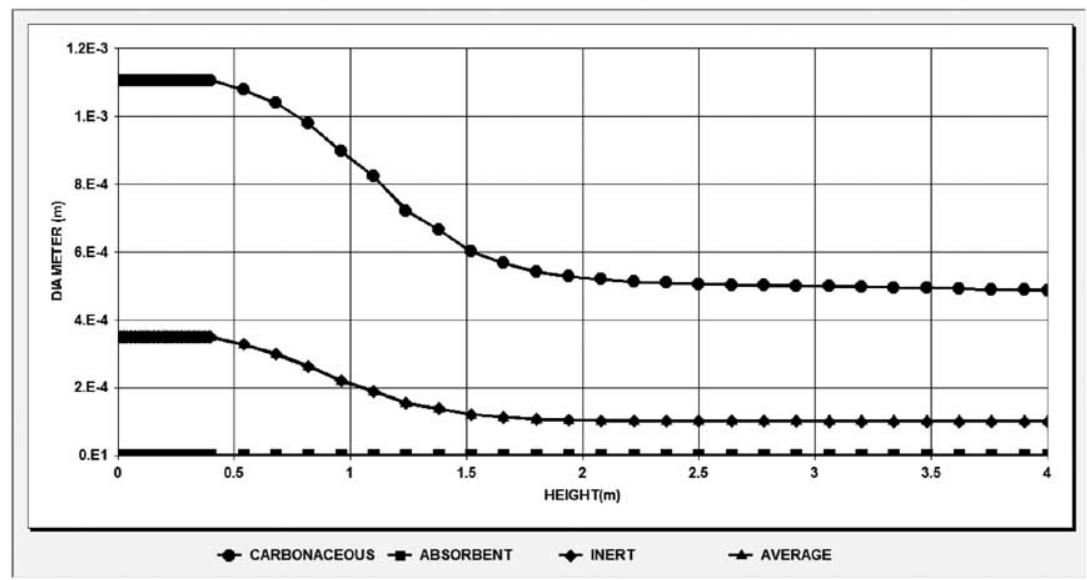

Fig. (9). Particle size averages throughout the dense and lean regions of a cold operation (test carried at UNICAMP).

(Fig. 9) and the usual correlations for the upward mass flow of particles in the lean region leads to the precise exponential or decrease against the height holds (Fig. 10). However, variations of temperature (Fig. 2) combined with fast changes on concentrations due to chemical reactions (Figs. 3 to 5) may distort that picture, as illustrated by Figs. (6 and 7). The fast gas-solid reactions either decrease the size of carbonaceous particles (if exposed core model) or their density (if unreacted core model) [1-4]. Since the unreacted-core model is adopted at the lean region, the particles retain their 


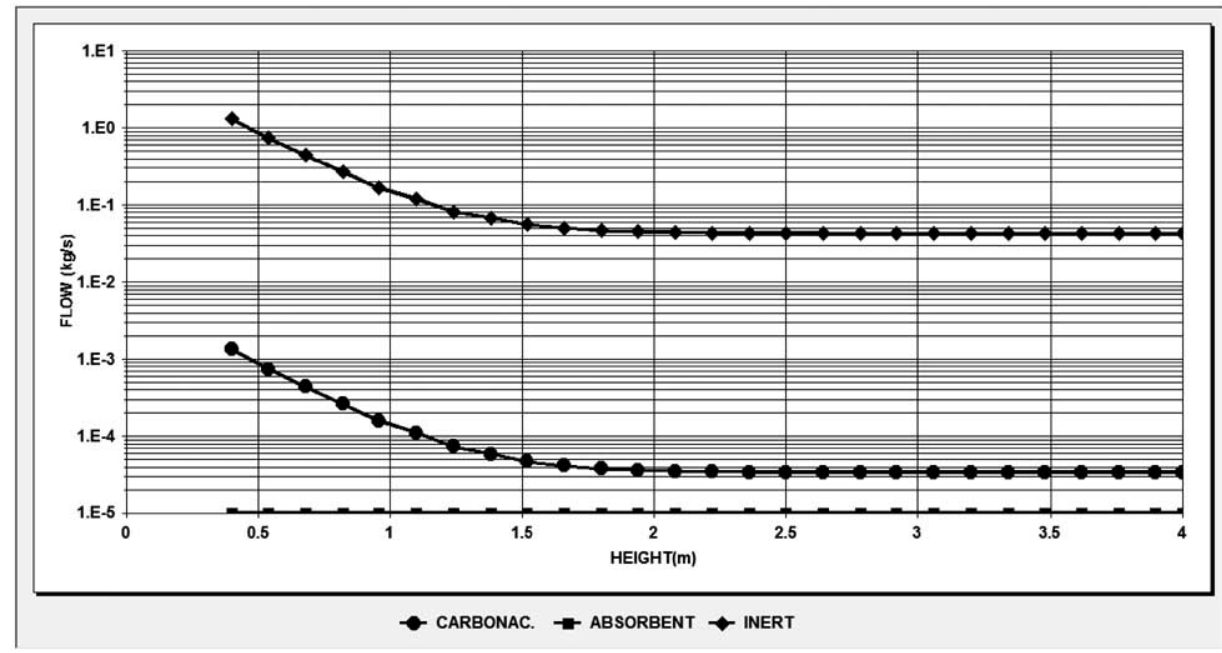

Fig. (10). Upward flow of solid particles throughout the lean region during cold operation (test carried at UNICAMP).

respective diameter but their density decreases. Therefore, particles that otherwise would return to the dense region, might be carried upward by the fast increasing mass flow of produced gases (Fig. 8). After the peak of temperature, the process leads to small variations in the average particle diameter (Fig. 6) and their total upward mass flow (Fig. 7) for higher positions in the lean region. This exemplifies the applicability and usefulness of the present comprehensive approaches, because they consider all factors combined in order to produce more realistic representations of real equipment operations.

\section{SCALING-UP}

From the above results, a first trial to scale-up the biomass gasification for industrial application has been made. For that the following criteria have been used:

a) Same consumed fuel. Of course, any scaling up of a pilot unit is applicable to the same fuel and any other particulate material fed into the bed. This includes not only the composition, physical properties, and particle size distributions.

b) Similar temperature, composition, and pressure of the gasifying agent. In the present case, a mixture of air and steam were applied during tests with the pilot unit. Equal conditions are set for the industrial-scale equipment.

c) Same superficial velocity. Combined with the above item, this would guarantee industrial unit operations under analogous fluidization conditions as found at the pilot.

d) Ratios between rates of fuel feeding and gasification agent injection are kept constant. This is another important point to ensure process equivalence between different scales.

e) Matching equipment height. If all above conditions are respected, the height for disengagement of particles may be maintained as in the pilot unit. However, some designers prefer to leave room for future increases in the output and might increase the total height as well. This is advisable because eventual changes in the fuel properties as well other input conditions to every industrial unit are very likely to occur.

Based on the above, the main dimensions of an industrial unit processing times the pilot one can be obtained. The pilot unit operation \#7 (see Tables $\mathbf{1}$ and 2) was selected for scaling-up and the basic dimensions of such a large unit are summarized below (Table 6).

Table 6. Basic Dimensions of the Scaled-Up Gasification Unit

\begin{tabular}{|l|l|}
\hline Basic Geometry & \\
\hline \hline Dense region equivalent diameter (m) & 5.34 \\
\hline Lean region equivalent diameter (m) & 5.34 \\
\hline Equipment height (m) & 6.500 \\
\hline Fuel feeding position (m) & 0.770 \\
\hline Injected fuel and gases & \\
\hline Feeding flow of fuel (kg/s) & 22.81 \\
\hline Air flow through distributor (kg/s) & 50.0 \\
\hline Temperature of injected air (K) & 433 \\
\hline Steam flow injected at 2 m above distributor $(\mathrm{kg} / \mathrm{s})$ & 0.554 \\
\hline Temperature of injected steam $(\mathrm{K})$ & 425 \\
\hline Average pressure in the equipment (kPa) & 105 \\
\hline
\end{tabular}

As seen, the scaling up had in mind a unit with power input around $400 \mathrm{MW}$.

CSFMB was applied and the main outputs are described in the tables below (Tables $\mathbf{7}$ and $\mathbf{8}$ ).

\section{CONCLUSIONS}

The main strategy of adapting the existing model and simulation program for bubbling fluidized bed equipment to cases of circulating ones have been shown. 
Table 7. Predicted Composition of Gas Produced from the Large Gasification Unit

\begin{tabular}{|c|c|}
\hline COMPONENT & MOLAR \% (d.b.) \\
\hline $\mathrm{H}_{2}$ & 6.8438 \\
\hline $\mathrm{H}_{2} \mathrm{~S}$ & 0.0524 \\
\hline $\mathrm{NH}_{3}$ & 0.1798 \\
\hline NO & 0.1181 \\
\hline $\mathrm{NO}_{2}$ & 0.0000 \\
\hline $\mathrm{N}_{2}$ & 60.8914 \\
\hline $\mathrm{N}_{2} \mathrm{O}$ & 0.0000 \\
\hline $\mathrm{O}_{2}$ & 0.0000 \\
\hline $\mathrm{SO}_{2}$ & 0.0405 \\
\hline $\mathrm{CO}$ & 10.4700 \\
\hline $\mathrm{CO}_{2}$ & 17.5861 \\
\hline $\mathrm{HCN}$ & 0.0013 \\
\hline $\mathrm{CH}_{4}$ & 3.8168 \\
\hline $\mathrm{C}_{2} \mathrm{H}_{4}$ & 0.0000 \\
\hline $\mathrm{C}_{2} \mathrm{H}_{6}$ & 0.0000 \\
\hline $\mathrm{C}_{3} \mathrm{H}_{6}$ & 0.0000 \\
\hline $\mathrm{C}_{3} \mathrm{H}_{8}$ & 0.0000 \\
\hline $\mathrm{C}_{6} \mathrm{H}_{6}$ & 0.0000 \\
\hline
\end{tabular}

The importance of a comprehensive approach in order to account for several phenomena occurring simultaneously has been illustrated. With that, a more realist picture of the processes taking place in circulating fluidized bed equipment can be obtained.

Several operational aspects of were discussed and comparisons against real operations showed that, even this first round of adaptation of a bubbling bed simulator to a circulating one, led to reasonable results or relatively low deviations.

CSFMB is capable of providing a considerable amount of information regarding internal and overall operational characteristics of boilers, gasifiers as well other processes, and complete lists of those are presented elsewhere [1-2].

Other experimental data would be soon available to the author. They may allow testing of new improvements on the model and simulation program. Such might lead to an even more reliable tool for studies on betterments of existing unit performances as well for optimal design of new circulating fluidized bed equipment and processes.

\section{ACKNOWLEDGMENTS}

The author is very grateful to Prof. John Grace and Dr. Xuantian Li for several details related to tests of circulating fluidized bed gasification conducted at the University of British Columbia. The gratitude should be extended to Prof.
Table 8. Few Operational Parameters Predicted for the Large Gasification Unit

\begin{tabular}{|l|l|}
\hline PROCESS PARAMETER & VALUE \\
\hline \hline Flue gas flow (kg/s) & 69.91 \\
\hline Flow of tar in exiting gas $(\mathrm{kg} / \mathrm{s})$ & 3.37 \\
\hline Flow of solids discharged from the dense region $(\mathrm{kg} / \mathrm{s})$ & 0.0173 \\
\hline Minimum fluidization velocity ${ }^{\text {a }}(\mathrm{m} / \mathrm{s})$ & 0.2494 \\
\hline Fluidization superficial velocity ${ }^{\text {a }}(\mathrm{m} / \mathrm{s})$ & 2.974 \\
\hline Mixing index in the dense region & 0.6474 \\
\hline Carbon conversion (\%) & 91.59 \\
\hline Mass held in the dense region (kg) & $1683 \mathrm{~kg}$ \\
\hline $\begin{array}{l}\text { Average residence time of particles in the system } \\
\text { based on the feeding rate (min) }\end{array}$ & 1.23 \\
\hline $\begin{array}{l}\text { Average residence time of particles in the system } \\
\text { based on the leaving rate (min) }\end{array}$ & 76.97 \\
\hline TDH (Transport Disengaging Height) (m) & \\
\hline Average temperature at distributor (K) & 4.05 \\
\hline Average temperature at bed middle (K) & 1106 \\
\hline Average temperature at bed top (K) & 1106 \\
\hline Average temperature at freeboard top (K) & 1106 \\
\hline Temperature at the recycling injection (K) & 1105 \\
\hline Dynamic bed height (m) & 1090 \\
\hline
\end{tabular}

${ }^{a}$ At the middle of the dense region.

Araí Pécora, which provided important information regarding the tests carried at UNICAMP.

\section{REFERENCES}

[1] M. L. de Souza-Santos, Solid Fuels Combustion and Gasification: Modeling, Simulation, and Equipment Operation. New York: Marcel Dekker, 2004.

[2] M. L. de Souza-Santos, "A new version of CSFB, comprehensive simulator for fluidized bed equipment", Fuel, vol. 86, pp. 16841709, 2007.

[3] M. L. de Souza-Santos, "Modelling and simulation of fluidized-bed boilers and gasifiers for carbonaceous solids", Ph.D. thesis, University of Sheffield, Sheffield, United Kingdom, 1987.

[4] M. L. de Souza-Santos, "Comprehensive modeling and simulation of fluidized-bed boilers and gasifiers", Fuel, vol. 68, pp. $1507-$ 1521, December 1989.

[5] M. L. de Souza-Santos, M. A. Cincoto, B. Pikman, A. H. Ushima, M. E. de Souza, "Fluidized-bed combustion of rice husks; experimental tests", in IV Brazilian Congress on Energy, Rio de Janeiro, RJ, Brazil, 1990, pp. 05-09.

[6] A. H. Ushima, R. Guardani, M. L. de Souza-Santos, "Determination of operational conditions for the reduction of $\mathrm{CaSO}_{4}$ to $\mathrm{CaS}$ in a fluidized bed", in IX Brazilian Congress on Chemical Engineering, Salvador, Bahia, Brazil, 1992.

[7] M. L. de Souza-Santos, "Comprehensive modeling and simulation of fluidized-bed reactors used in energy generation processes", in Meeting on Energy Modeling: Optimizing Information and Resources, Institute of Gas Technology, Chicago, 1993.

[8] M. L. de Souza-Santos, "Application of comprehensive simulation to pressurized fluidized bed hydroretorting of shale", Fuel, vol. 73, pp. $1459-1465,1994$. 
[9] M. L. de Souza-Santos, "Application of comprehensive simulation of fluidized-bed reactors to the pressurized gasification of biomass", J. Braz. Soc. Mech. Sci., vol. XVI, No. 4, pp. 376-383, 1994.

[10] M. L. de Souza-Santos, "A Study on pressurized fluidized-bed gasification of biomass through the use of comprehensive simulation", in Fourth International Conference on Technologies and Combustion for a Clean Environment, Lisbon, Portugal, 1997, p. 25.2, vol. II.

[11] M. L. de Souza-Santos, "Search for favorable conditions of atmospheric fluidized-bed gasification of sugar-cane bagasse through comprehensive simulation", in 14th Brazilian Congress of Mechanical Engineering, Bauru, São Paulo, Brazil, 1997.

[12] M. L. de Souza-Santos, "Search for favorable conditions of pressurized fluidized-bed gasification of sugar-cane bagasse through comprehensive simulation", in14th Brazilian Congress of Mechanical Engineering, Bauru, São Paulo, Brazil, 1997.

[13] M. L. de Souza-Santos, "A study on pressurized fluidized-bed gasification of biomass through the use of comprehensive simulation", in Combustion Technologies for a Clean Environment: Gordon and Breach Publishers, Amsterdam, Holland, 1998, vol. 4, Chapter 4.

[14] M. L. de Souza-Santos, "A feasibility study on an alternative power generation system based on biomass gasification/gas turbine concept", Fuel, vol. 78, pp. 529-538, 1999.

[15] A. M. S. Costa, M. L. de Souza-Santos, "Studies on the mathematical modeling of circulation rate of particles in bubbling fluidized beds", Powder Technol., vol. 103, pp. 110-116, 1999.

[16] P. D. Leveson, M. L. de Souza-Santos, "Improvements on the modeling of sulphur dioxide emissions from fluidized bed combustors and gasifiers", in ENCIT 2000 - 8th Brazilian Congress of Thermal Engineering and Sciences, Porto Alegre, R.S., Brazil, 2000.

[17] J. A. Rabi, M. L. de Souza-Santos, “A two-parameter preliminary optimization study for a fluidized-bed boiler through a comprehensive mathematical simulator", in ENCIT 2000 - 8th Brazilian Congress of Thermal Engineering and Sciences, Porto Alegre, R.S., Brazil, 2000.

[18] M. L. de Souza-Santos, "Two trial models for the rate of combustion and gasification of liquid fuels sprayed on inert fluidized particles", in Sixth International Conference on Technologies and Combustion for a Clean Environment, Porto, Portugal, 2001.

[19] M. L. de Souza-Santos, "Two trial models for the rate of combustion and gasification of slurries or liquid biomass sprayed on inert fluidized particles", in Fifth Biomass Conference of the Americas, USA, Orlando, Florida, 2001.

[20] J. A. Rabi, M. L. de Souza-Santos, "Preliminary improvements in the radiative heat transfer modeling for fluidized bed biomass gasification: bed section", in Fifth Biomass Conference of the Americas, Orlando, Florida, USA, 2001.

[21] J. A. Rabi, M. L. de Souza-Santos, "Incorporation of a 2-flux model for radiative heat transfer in a comprehensive fluidized bed simulator. Part I: Preliminary model equations", 9th Brazilian Congress on Engineering and Thermal Sciences, Caxambu, Minas Gerais, Brazil, 2002.

[22] J. A. Rabi, M. L. de Souza-Santos, "Incorporation of a 2-flux model for radiative heat transfer in a comprehensive fluidized bed simulator. Part II: Numerical results and assessment", 9th Brazilian Congress on Engineering and Thermal Sciences, Caxambu, Minas Gerais, Brazil, 2002.

[23] J. A. Rabi, M. L. de Souza-Santos, "Incorporation of a two-flux model for radiative heat transfer in a comprehensive fluidized bed simulator. Part I: Preliminary theoretical investigations", Therm. Eng., vol. 3, pp. 64-70, 2003.

[24] J. A. Rabi, M. L. de Souza-Santos, "Incorporation of a two-flux model for radiative heat transfer in a comprehensive fluidized bed simulator. Part II: Numerical results and assessment”, Therm. Eng., vol. 4, pp. 49-54, 2004.

[25] P. J. van den Enden, E. S. Lora, "Design approach for a biomass fed fluidized bed gasifier using the simulation software CSFB", Biomass Bioenerg., vol. 26, pp. 281-287, 2004.

[26] D. Geldart, Gas Fluidization Technology. Chichester, U.K.: John Wiley, 1986.

[27] A. A. B. Pécora, "Study of the fluid dynamics of circulating fluidized beds with secondary air injection", $\mathrm{PhD}$ thesis, University of Campinas, Campinas, SP, Brazil, 1995.

[28] A. B. Pécora, L. Goldestein Jr., "A fluid dynamics study of circulating fluidized beds with secondary air injection", ASME Heat Transf. Div., vol. 334, pp. 287-292, 1996.

[29] A. B. Pécora, L. Goldestein Jr., "A fluid dynamics model of circulating fluidized bed with secondary air injection", in VII Latin American Congress on Heat and Mass Transfer (LATCYM), pp. 245-249, 1998.

[30] K. Kato, H. Shibasaki, K. Tamura, S. Arita, C. Wang, T. Takarada, "Particle holdup in a fast fluidized Bed", J. Chem. Eng. Jpn., vol. 22, pp. 130-136, 1989

[31] J. H. Choi, C. K. Yi, J. E. Son, "Axial voidage profile in a cold mode circulating fludized bed', in $3^{\text {rd }}$ International Conference On Circulating Fludized Beds, Nagoya, Japan, 1991, pp. 4.9.1-4.9.6.

[32] Y. Li, B. Chen, F. Wang, Y. Wang, M. Kwauk, "'Rapid fluidization", Int. Chem. Eng., vol. 21, pp. 67-678, 1981.

[33] M. Kwauk, N. Wang, Y. Li, B. Chen, Z. Shen, "Fast fluidization at ICM", in Circulating Fluidized Bed Technology, P. Basu, Ed., New York: Pergamon Press, 1986.

[34] J. Li, Y. Tung, M. Kwang, "Axial voidage profiles of fast fluidized beds in different operating regions", in Circulating Fluidized Bed Technology II, P. Basu, J. F. Large, Eds., New York: Pergamon Press, 1988.

[35] D. Subbarao, "Clusters and lean-phase behavior", Powder Technol., vol. 46, pp. 101-107, 1986.

[36] M. J. Rhodes, D. Geldart, "A model for the circulating fluidized bed", Powder Technol., vol. 53, pp. 155-162, 1987.

[37] D. Kunii, O. Levenspiel, "Flow modeling of fast fluidized beds", in $3^{\text {rd }}$ International Conference of Circulating Fluidized Beds, Nagoya, Japan, 1990, pp. 4.7.1-4.7.8.

[38] H. Zhang, Y. Xie, Y. Chen, M. Hasatani, "Mathematical modeling for longitudinal voidage distribution of fast fluidized beds", in $3^{\text {rd }}$ International Conference of Circulating Fluidized Beds, Nagoya, Japan, 1990, pp. 4.13.1-4.13.6.

[39] M. J. Rhodes, "Modeling the flow structure of upward-flowing gassolid suspensions", Powder Technol., vol. 60, pp. 27-38, 1990.

[40] W. C. Yang, "A model for the dynamics of circulating fluidized bed loop", in Circulating Fluidized Bed Technology II, J. F. Large, P. Basu P., Ed. New York: Pergamon Press, 1988, pp. 181-191.

[41] C. Kefa, F. Jianren, L. Zhongyang, Y. Jianhua, N. Mingjiang, "The prediction and measurement of particle behavior in circulating fluidized beds", in Circulating Fluidized Bed Technology II, J. F. Large, P. Basu, Ed. New York: Pergamon Press, 1988, pp. 27-131.

[42] F. Berruti, N. Kalogerakis, "Modeling the internal flow structure of circulating fluidized beds", Can. J. Chem. Eng., vol. 67, pp. 1010$1014,1989$.

[43] R. Guardani, "Characterization of fluid dynamics and mathematical modeling of circulating fluidized bed reactor", $\mathrm{PhD}$ thesis, Department of Chemical Engineering, Polytechnic School, University of Sao Paulo, 1989.

[44] C. Y. Wen, L. H. Chen, "Fluidized Bed Freeboard Phenomena: Entrainment and Elutriation", AIChE J., vol. 28, pp. 117, 1982.

[45] R. D. Toomey, H. F. Johnstone, "Gaseous Fluidization of Solid Particles", Chem. Eng. Prog., vol. 48(5), pp. 220-226, 1952.

[46] X. T. Li, J. R. Grace, C. J. Lim, A. P. Watkinson, H. P. Chen, J. R Kim, "Biomass gasification in a circulating bed", Biomass Bioenerg., vol. 26, pp. 171-193, 2004.

[47] J. R. Grace, C. M. H. Brereton, C. J. Lim, R. Legros, J. Shao, R. C. Senior, R. L. Wu, J. R. Muir, R. Engman, "Circulating fluidized bed combustion of western Canadian fuels", Final Report prepared for the Energy Mines and Resources of Canada under contract 52ss.23440-7-9136, 1989.

(C) Marcio L. de Souza-Santos; Licensee Bentham Open.

This is an open access article licensed under the terms of the Creative Commons Attribution Non-Commercial License (http://creativecommons.org/licenses/by-nc/3.0/) which permits unrestricted, non-commercial use, distribution and reproduction in any medium, provided the work is properly cited. 